\title{
Os dramas da cidade nos jornais de São Paulo na passagem para o século XX
}

\author{
Valéria Guimarães \\ Pós-doutoranda em Comunicação - COS-PUCSP
}

\section{RESUMO}

Este artigo trata das representações da cidade de São Paulo feitas pelo jornal $O$ Estado de S. Paulo em 1910, e da censura à imprensa, através de um Relatório de Justiça, por esta divulgar casos de suicídios no estilo de fait divers, na passagem do século XIX para o XX. Partimos da hipótese de que a postura do relator fazia parte de uma extensa ação disciplinadora de controle da cidade, à qual a imprensa não escapava. Tal ação disciplinadora estava pautada pelas teorias racistas e deterministas de matriz européia e articulava diversas instâncias do poder. Aplicadas de modo particular ao contexto brasileiro em razão do passado escravista, a tentativa de ordenamento da cidade agrega o racismo de cor ao de classe, redimensionado no novo contexto republicano.

Palavras-chave: Imprensa; Fait divers; Cidade.

\section{ABSTRACT}

This article is about representations of the city of São Paulo made by the periodical O Estado de S. Paulo in 1910 and analyses a case of censorship towards the media, through a Report of Justice, related to the divulgation of fait divers style suicide cases in the period of transition between the $19^{\text {th }}$ and the $20^{\text {th }}$ centuries. We start from the following hypothesis: the position of the author of the Report was influenced by an extensive disciplinary action set up to control the city and that targeted also the media. Such disciplinary action was based on racist and determinist theories, of european matrix, and articulated various levels of power. Applied to this particular Brazilian context due to its legacy of slavery, the attempt to put order in the city joins the racism to social exclusion, adapted to the New Republican era. Keywords: Press; Fait divers; City. 
Ele ia ao Palácio das Indústrias. Parou na ponte de pedra sobre o Tamanduateí que transbordava em lago, depois dormia em canal para as bandas da Luz. Havia olhos vigilantes de torres, fixos, longe. E lampiões e a cidade e estrelas no céu... E a correnteza embaixo, redobrada e murmurante.

O íncubo disse-lhe ao ouvido:

- Se te atirasses, ias sair na excrementeira da cidade...

Oswald de Andrade

Na passagem do século XIX para o XX ocorreu um fenômeno editorial na imprensa diária das maiores cidades brasileiras, como Rio de Janeiro e São Paulo, que logo serviu de modelo para o novo jornalismo praticado a partir de então no Brasil: os jornais de maior circulação começaram a publicar em suas seções de fatos diversos notícias sensacionalistas, já muito comuns na imprensa européia e norte-americana.

O crescimento das cidades e a maior ocorrência de crimes, por exemplo, dava assunto ao noticiário que cobria o cotidiano. Também conhecidas como fait divers, essas crônicas policiais, que também traziam prodígios de todo tipo, eram contadas de modo dramático, por vezes com laivos cômicos, povoando os jornais com cenas violentas ou absurdas. ${ }^{2}$ Com essa fórmula, a imprensa, que se torna um empreendimento empresarial à época, tenta atrair leitores. ${ }^{3}$ A tradução para o termo seria 'fatos diversos', mas normalmente a expressão é usada no original.

Já em fins do século XIX esses textos eram muito comuns, mesmo em jornais 'sérios' como O Estado de S. Paulo. Por notícia 'séria' entendemos aquela que é comprometida com a informação fidedigna, passível de ser checada e que corresponde à ética de um jornalismo a serviço da comunidade. Esse contraponto é importante, pois está entre as características do fait divers o empréstimo de recursos da ficção para tornar a notícia a um só tempo mais interessante ao leitor e menos violenta, amenizando a cena de sangue com recursos narrativos. Isso o aproxima do entretenimento e o distancia da busca da 'verdade'.

Logo surgiram algumas manifestações contra o teor do que viria a ser nomeado de imprensa marrom. ${ }^{4}$ Uma delas, um trecho de um Relatório de Justiça de 1894 que veremos adiante, censura os jornais por publicarem crônicas de suicídios de forma sensacionalista, delatando o poder de contágio desse tipo de leitura. Era uma forma de advertir essa mesma imprensa sobre o seu papel de agente civilizador. 
Nossa hipótese consiste em afirmar que o olhar do relator lançado a esses veículos, em tom de advertência, é parte de uma ação disciplinadora mais ampla em que a noção do que chamamos de 'degeneração' é pautada pela influência de teorias de cunho científico que serviram de referência para a intervenção urbana em São Paulo na passagem do século XIX para o XX, momento em que a cidade encontrava-se em amplo crescimento.

A fórmula sensacionalista, porém, vigorou a despeito das advertências oficiais. Assim, podemos observar em uma crônica de 1910, a ser analisada neste artigo, a representação da cidade de São Paulo e de seus cidadãos pelas lentes de um cronista cujo discurso também estava impregnado das referências do cientificismo e do determinismo biológico, mas que, contrariando a orientação oficial, acabava por revelar um lado da cidade que se queria oculto dentro da representação ufanista. ${ }^{5}$

Tido por a-histórico e 'universal', é Marc Ferro que resgata a historicidade do fait divers reivindicando sua relação com o contexto. Esse historiador denuncia que por muito tempo o fait divers, para a 'ciência histórica', não era história. ${ }^{6}$ Apesar de Roland Barthes ${ }^{7}$ e George Auclair, ${ }^{8}$ de forma pioneira, terem resgatado o fait divers, dando-lhe uma identidade, continuava a ser visto como um "fato sem contexto".

Aceitando o desafio de relacionar o fait divers com seu contexto histórico e, assim, resgatar sua historicidade, temos que, com sua leitura, se abre uma janela para os dramas da cidade, revelando uma face do cotidiano de cidadãos anônimos em situações as mais dramáticas, que vão de crimes passionais a brigas, atropelamentos, assaltos e suicídios.

Cabe a observação sobre a legitimidade do uso desse tipo de fonte na pesquisa histórica. Se por um lado sabemos que o escritor de fait divers talvez não esteja preocupado com a veracidade, como qualquer outro autor de ficção, sabemos também que ele fala de seu tempo suscitando alguns indícios culturais. O que ele nos traz não é o reflexo de uma realidade mas possibilidades que, articuladas, podem nos legar algumas representações de situações da época por vezes absolutamente possíveis tais como as privações financeiras, o desespero ou as situações-limite que estão no âmago de ações criminosas.

Sem entrar na discussão da natureza da narrativa histórica e da narrativa de ficção, que no caso do híbrido fait divers resultaria em um artigo à parte, nos propomos a levantar questões sobre alguns dados que esse texto nos dá através de construções intelectuais de certos grupos sociais, encaradas como focos de tensões e conflitos que emergem das temporalidades descontínuas em que se inserem. ${ }^{10}$ 
Normalmente narrados sem nenhum compromisso social, acabavam por difundir estigmas. $\mathrm{O}$ cronista acabava por fixar tais indivíduos como personagens malditos e degenerados, atribuindo a eles qualidades depreciativas de cunho racista. Uma representação da cidade que ecoa um repertório compartilhado, parte da campanha da regeneração na qual a imprensa da época estava engajada. ${ }^{11}$ Neles vem descrita a parte não nobre da cidade, os cortiços e os becos, os rios sujos e insalubres, as várzeas e as ruas de bairros pobres.

Há quem transformasse com talento a crônica de fait divers em crônica literária, caso de João do Rio e Nelson Rodrigues. Há quem se comovesse com aqueles anônimos a saltarem de pontes, a matarem por amor, a renunciarem à vida por causa de seus desesperos, como Lima Barreto, Alcântara Machado ou, mais tarde, Sérgio Porto.

Mas, a maioria dos contemporâneos via o fait divers como resultado da falta de cultura e refinamento e, quando pior, uma fórmula perigosa, considerando-o peça destoante ao processo de modernização encampado pelas elites de então por revelarem, entre outros motivos, o lado sombrio da cidade, alvo das políticas higienizadoras.

Vejamos uma dessas crônicas publicada em 1910 n'O Estado:

\section{Mais um desesperado}

Tentativa de suicídio no rio Tamanduateí — ato de heroísmo de um cabo da guarda cívica - amores mal correspondidos

O menor José Quintino da Rocha, de 19 anos de idade, empregado da 'Light', morador à travessa Tibiriçá, 5 , de há muito que anda desgostoso por motivos a que não são alheios a paixão e a falta de recursos.

José ama desesperadamente uma operária da fábrica Matarazzo. Esta, por sua vez, não lhe é indiferente, porém, segundo o depoimento de algumas pessoas que os conhecem, o namoro já vem de muito longe e os pais da jovem operária marcaram um prazo para o casamento.

José tem pensado muito, porém o seu pequeno salário mal chega para suas despesas, quanto mais para sustentar sua mulher.

E José principiou a ficar triste e abatido, não indo à casa da noiva há mais de uma semana.

Anteontem entrou ele no 'Cinema Popular', à avenida Rangel Pestana, e ali viu a sua adorada trocando olhares ternos com um rapaz alto e moreno, que vestia um elegante costume de casimira clara.

José ficou como louco. Pensou em tomar satisfações da noiva e do seu conquistador. Muitas vezes teve ímpetos de se precipitar sobre ambos e cortar-lhes as car- 
nes com a navalha que trazia na algibeira, a qual apertava nervosamente. $\mathrm{O}$ amor, porém venceu todos esses ímpetos raivosos e o desventurado moço não esperou terminar a sessão cinematográfica: saiu para a rua com a cabeça a escaldar.

Não foi para casa, vagou a noite toda e ontem seguiu pela avenida Cantareira, margeando o rio Tamanduateí. De repente, atirou para o lado o chapéu e precipitou-se na água.

Não longe do infeliz moço vinha o cabo da guarda cívica Zoroastro Ferreira de Moura, $\mathrm{n}^{\circ} 72$ da primeira companhia. Zoroastro, percebendo as intenções de José, correu para o local vendo então o jovem a debater-se horrorosamente nas águas.

Zoroastro com uma coragem extraordinária e arriscando a própria vida atirou-se também na água, conseguindo a muito custo trazer para a margem do rio o corpo desfalecido do moço José.

Dali foi ele conduzido para o posto de São Caetano, onde foram tomadas as declarações.

O dr. Cantinho Filho, primeiro delegado, enviará hoje ao comandante da guarda cívica, pedindo para que o cabo Zoroastro seja elogiado no dia pelo seu ato de heroísmo. ${ }^{12}$

Há nesse relato o tom exagerado, extraordinário, romântico e dramático da narrativa, características de fait divers. Seus temas se inspiram na realidade e facilmente estão envoltos pela contradição, pelo patético e pela presença da ficção explícita, não tendo compromisso com a informação. Sua fórmula reúne fato e invenção ao mesmo tempo, a ponto de estas se confundirem, tênue linha separando real e imaginação.

Destaca-se o endereço, o que dá credibilidade à história, e a profissão. Porém, mais que credibilidade, tais referências ajudam a marcar o lugar ocupado pelos 'personagens' na sociedade: jovens, em idade produtiva e reprodutiva, e pobres. Aparentemente essa crônica relaciona a tentativa de suicídio apenas com problemas financeiros, tema de tantas outras que povoavam as páginas da seção Notícias Diversas no jornal O Estado de S. Paulo. Mas, os jornalistas sempre concluem que o fator determinante é de ordem moral, fazendo que o registro se esquive do seu fundo social.

De qualquer forma, a crônica nos leva a um passeio pela São Paulo antiga, deixando vestígios da atuação dos 'personagens' na cidade e de como ocorria a circulação de idéias.

Temos nessa crônica, portanto, a história de um jovem operário, empregado da Light, empresa canadense que monopolizava os serviços de forneci- 
mento de energia na capital paulista e que foi altamente favorecida pelo processo especulativo que cercou a urbanização da cidade, expandindo seus serviços por bairros recém-arruados. ${ }^{13}$

Morava à rua Tibiriçá, que ficava no Bom Retiro. Esse era um bairro fabril e proletário, uma várzea do rio Tietê, o que o deixava sujeito a freqüentes enchentes. Tinha um dos maiores índices de epidemias de São Paulo. Seus poços de água eram insalubres e seus terrenos residenciais, estreitos e compridos, com cinco ou seis metros de frente, alinhavam em seus corredores várias casinhas onde moravam numerosas famílias. ${ }^{14}$

Apresentava a maior concentração de fábricas depois do Brás, ${ }^{15}$ e o comércio era igualmente intenso, por ser passagem para a Estação da Luz, dominado em sua maioria por vendas de portugueses onde se encontravam bacalhau, sardinha, arroz, feijão e pão.

Árabes, judeus e italianos compunham sua eclética população. Nele estavam localizadas a Escola de Farmácia e Odontologia, fundada em 1904, que atendia aos moradores, e a Escola Politécnica, de 1893, o que fazia circular por suas ruas um grande número de estudantes. ${ }^{16}$ Mas a freqüência aos cursos superiores era restrita às camadas mais abastadas da população, o que parece não ser o caso de José.

Para o leitor de jornais da época, não era preciso dar esses detalhes. A simples referência a empregado da Light e bairro do Bom Retiro expunha a pobreza de José e a face da cidade que o progresso não havia atingido, sempre ratificando o lugar físico e social que o rapaz ocupava na cidade.

O motivo da desgraça desse rapaz de 19 anos era, além da pobreza, uma mulher, uma jovem que, se "não lhe é indiferente", não lhe dedicava um amor incondicional independente das circunstâncias. E as circunstâncias não eram as melhores para José. Os pais, como responsáveis pelo futuro da filha, marcaram prazo para a cerimônia, que estava condicionada à possibilidade de ele poder assumir o compromisso de cuidar dela.

A mulher aparece aqui como posse e como criança, que precisa de cuidados a serem transferidos do pai para o marido. Esse momento histórico assiste a uma redefinição da família onde a mulher é imaginada como contida, "voltada para a intimidade do lar". ${ }^{17} \mathrm{O}$ casamento, por sua vez, era visto como uma instituição que garantia a coesão da família, a estabilidade e organicidade desta que era considerada pelos contemporâneos a célula básica da sociedade. Ao mesmo tempo, era a principal arma no combate à mestiçagem e tinha uma função evolutiva. ${ }^{18}$ Em um Anuário Estatístico de Demografia, rela- 
tivo ao ano de 1903, o casamento é tido como meio de prevenção à loucura, ao suicídio e à criminalidade.

O valor do casamento é muito conhecido para que insistamos em dizer qual ele é; sabe-se demais o papel que ele representa, sua influência sobre a mortalidade, que é sempre maior nos solteiros ... Ninguém ignora que estas influem sobre a criminalidade; $\mathrm{O}$ casamento reduz o perigo da alienação mental de perto da metade, é uma fonte que, se não esgota o mal, pelo menos o alivia de muito e sobre o suicídio é tão pronunciada sua ação, que na opinião de Proust o celibato e a viuvez constituem uma causa forte e ativa do suicídio nos dois sexos. O casamento é pois útil ao indivíduo e à sociedade, conserva a saúde de um e eleva a moral da outra. ${ }^{19}$

É bem possível que a pressão pelo casamento possa ser entendida em vista dessa percepção de que a família deveria estar encarregada de propiciar a criação de uma nova célula, assegurando isso à sua prole, em especial às jovens. A contar com as palavras do cronista, o prazo fixado para a tomada de atitude de José Quintino era legítima, visto que "o namoro já vem de muito longe" o que era corroborado pelo "depoimento de algumas pessoas que os conhecem", fazendo supor um repertório compartilhado.

Confrontando esse panorama com o Anuário Estatístico, a idéia do casamento como necessário, até mesmo vital, fator profilático da loucura e do suicídio, sendo seu "valor ... muito conhecido para que insistamos em dizer qual ele é”, era corrente no imaginário da época. Ainda que os conflitos de José sejam resultado da imaginação do cronista, tal representação da instituição do matrimônio era corrente, ${ }^{20}$ tornando a crônica plausível.

A tensão presente na narrativa entre a obrigação do casamento e as condições financeiras do rapaz, traz à tona a tentativa de ordenamento social então existente através de medidas oficiais de sistematização e análise de dados, como o Anuário Estatístico de Demografia, com vistas a assegurar a organicidade e o equilíbrio do funcionamento da cidade, a despeito das reais condições de sua população.

Além da falta de dinheiro, a princípio não existiam outros empecilhos para o casamento dos jovens como, por exemplo, a cor da pele. Ambos eram provavelmente brancos, já que era praxe da imprensa apresentar a cor da pele aos seus leitores. Dentro de uma sociedade extremamente hierarquizada, de forte tradição racista, cujas teorias científicas eram não só aceitas como rea- 
firmadas a todo instante com base em 'evidências', esse era um dado que implicava muita coisa.

Neste caso o próprio fato de a menina ser operária já quase excluía a possibilidade de ser negra, visto a predileção pela mão-de-obra branca ou estrangeira, seja por questões racistas, seja pela preferência aos patrícios. ${ }^{21}$ Aos nacionais, sobretudo se mestiços ou negros, eram atribuídas as tarefas mais pesadas - estivadores, carregadores, carvoeiros, lenheiros, coletores de lixo ou carroceiros, entre outros. ${ }^{22}$

Muito se falou sobre a incapacidade dos ex-escravos e seus descendentes para o trabalho da indústria, relacionada a uma suposta incompetência e inadaptação destes à especialização da produção fabril, o que não faz sentido já que os imigrantes europeus também provinham, em sua maioria, de regiões agrícolas. O racismo é tão evidente que ainda havia o fato de ser explorada ao limite a mão-de-obra infantil, em nada mais especializada que um adulto, naturalmente, sempre em detrimento do emprego de braços dos afro-descendentes. ${ }^{23}$

No caso de José Quintino, ele é descrito como trabalhador, o que tinha uma conotação altamente positiva. Mas não tinha dinheiro para formar uma família. Isso abalou de tal forma o rapaz, sempre de acordo com o cronista, que o levou a uma depressão crescente: "E José principiou a ficar triste e abatido, não indo à casa da noiva há mais de uma semana".

Dava-se, então, um movimento paradoxal. José era bom porque trabalhador e vítima do vil metal. Mas era um condenado aos sentimentos degenerados, porque não se mostrava forte o suficiente para superar os desafios impostos.

No entanto, não era esse o único fator que levava José a ser "mais um desesperado", título da crônica que faz crer que os casos de suicídios não eram poucos. Mas também os olhares que a sua namorada trocava com outro, o que poderia ser julgado à época como má índole.

A princípio fica a imagem de uma moça trabalhadora, branca, pobre, para quem o casamento poderia ser uma chance de ascensão social ou, pelo menos, de sustento assegurado; isso José não poderia propiciar, abrindo espaço para o rival. Mas o fato de que ela esteve "trocando olhares com outro", faz sua reputação ser questionável. "Não é a mulher esta carne fraca, presa fácil das paixões, que sucumbe sem resistências ao olhar insistente ou aos galanteios envaidecedores do sedutor?". ${ }^{24}$

O cronista deprecia a jovem operária ao mostrá-la como essa 'presa fácil'. É a imagem em tudo oposta à da moça de família contida, estando mais 
voltada para o retrato de uma mulher "carnal e egoísta - encarnação do mal". ${ }^{25}$ Sua representação é das mais depreciativas, como se deduzisse sua índole de sua posição social. Como não podemos averiguar se ela de fato trocou olhares, é possível supor que o cronista tenha inventado esse trecho da trama com base em estigmas difundidos que relacionavam mulheres pobres com lascívia.

É então que aparece o cinema do bairro pobre, o lugar propício da bolinação, escuro e facilitando a proximidade dos corpos, um lugar em que uma moça de família não deveria estar, se assim realmente fosse. ${ }^{26} \mathrm{O}$ Cinema Popular, surgido na década de 1910, é contemporâneo de outros cinemas de bairro como o Ísis e o Ideal, na rua do Gasômetro, no Brás; o Cine Belém, inaugurado em 1911 na própria Celso Garcia, no bairro do Belenzinho; o Cine $\mathrm{Pa}$ vilhão, no bairro em que José Quintino da Rocha morava, Bom Retiro; o Cine Teatro Recreio (1911), Cine Santa Maria (1914) e o Lapa Cinema (1915), no bairro afastado da Lapa. Os ingressos cobrados nessas salas eram mais baratos do que os dos cinemas do centro da cidade e dos teatros, garantindo um público maior.

Suas instalações eram comumente simples, imensos barracões de zinco, como era descrito o Cine Belém por Jacob Penteado. ${ }^{27}$ Seus freqüentadores eram os próprios moradores dos bairros pobres. Para o leitor do Estado tais explicações eram desnecessárias: a simples alusão ao tipo de cinema que José, a namorada e o sedutor moreno freqüentavam já denotava o fato de serem pobres.

Ir ao cinema era um programa muito popular em São Paulo no início do século XX. Seu encanto desbancou a fotografia e outras técnicas que o precederam com a intenção de recuperar a aparência de realidade da imagem vista em profundidade, como a fotografia em três dimensões. Esta última havia virado moda, circulando até mesmo em cartões-postais. Neste caso, o uso de estereoscópios tornava a fotografia ' 3 -D' muito inferior ao cinema, que dispensava qualquer tipo de intermediário entre o olho e o objeto visualizado, além, é claro, da recuperação do movimento que a "fotografia animada" ${ }^{28}$ proporcionava.

Assistir a um filme, então, torna-se uma experiência que dá ilusão da própria experiência de realidade, ${ }^{29}$ pois os objetos adquirem relevo e detalhe, enquanto elementos subliminares "são utilizados pelos cineastas para produzir impactos afetivos". ${ }^{30}$ Percepção, imaginação e noção são tocados pela imagem fulgurosa da emanação de luz da tela a resplandecer na obscuridade do ambiente, um estímulo ultraluminoso que "de certo modo hipnotiza o especta- 
dor", estado facilitado pelo "desaparecimento de estímulos sensoriais concomitantes, relativos à vida real"."1

O primeiro fator sugestivo que há que ter em conta é o ambiente escuro em que o espectador deve submergir para poder completar a imagem. A pouca luz produz um isolamento exterior e reconcentra o espectador, evitando-lhe toda distração. Assim o espectador fica disponível e aberto para a influência que o cinema queira exercer sobre ele. ${ }^{32}$

José, então preterido pela operária, entra no Cinema Popular. Se os pormenores sobre sua intimidade já levam o leitor a desconfiar de que o cronista toma certa 'liberdade' para narrar os 'fatos', é nesta ação do acaso, com José, por coincidência, encontrando sua namorada no cinema a trocar olhares com outro, que o relato torna-se ainda mais fantástico. A ação do destino leva a um dos ápices da narrativa, que é a traição. Fórmula bem conhecida dos folhetins e romances, aqui parece que o escritor não faz questão de esconder que faz ficção com base em fatos reais, intervenção que visa tornar a narrativa mais atraente para o leitor. ${ }^{33}$

Nesse panorama, é interessante que a notícia destaque a indumentária do rapaz alto e moreno que "vestia um elegante costume de casimira clara". Há um deslocamento aí. O fato de ser moreno e estar num bairro pobre, não o faz provavelmente bem-vestido. Talvez o rival de José fosse um cáften. Não é possível averiguar, ainda mais dentro de uma atmosfera permeada pela ficção. Mas os elementos desestabilizadores, a falta de dinheiro e o rival de José parecem denotar uma realidade plausível: a moça pobre que se deixa seduzir por um rapaz de boa aparência que, por sua vez, pretende explorar sua ingenuidade.

Clichês muito explorados pela literatura que, provavelmente, o cronista toma para si, elaborando uma narrativa possível na realidade, embora fantasiosa em seus termos, esvaziando um pouco a desgraça 'real' para torná-la tão interessante quanto literatura.

Diante dessa cena, os ciúmes: José fica louco. A razão deste, então, desaparece. A depressão dá lugar à loucura e a cena violenta é desenhada em meio à confusão dos pensamentos, que se sobrepõem na velocidade de acontecimentos simultâneos como simultânea era a vida na cidade, como simultâneas são as cenas de um folhetim: tomar satisfação com ambos, partir para briga e "cortar-lhes as carnes com a navalha que trazia na algibeira a qual apertava 
nervosamente", ou resignar-se ao "amor [que] venceu todos esses ímpetos raivosos".

Aqui outro fator que marginaliza José, além de sua pobreza. A despeito de trabalhador e honesto, José andava armado. Como herói, resistindo à tentação de usar a arma, sai do ambiente escuro do cinema e procura a luz fora dele. Foi sua decisão ainda "com a cabeça a escaldar". Então a cidade aparece novamente como palco para o 'desesperado', 'pobre', 'apaixonado', que 'ama desesperadamente', 'triste' e 'abatido' José, que por pouco não se torna um homicida, 'raivoso', 'desventurado' e 'louco', a vagar durante toda noite até acabar como um 'suicida' mal-sucedido. Não é dito aonde ele foi, por onde esteve, como se à noite a cidade não pudesse ser revelada. Sua função comercial não se mostra durante a noite, hora dos marginais, dos rendez-vous, das prostitutas e dos boêmios.

Ao amanhecer, seu roteiro: Rangel Pestana, avenida Cantareira, margeando o Tamanduateí até lançar-se a este rio "insalubre, espraiado, com inundações, viveiro inóspito de miasmas". ${ }^{34}$

A Rangel Pestana era a principal avenida do Brás, por onde passavam os bondes elétricos que faziam ponto final ali, no Belém e na Penha. As linhas de trem da São Paulo Railway a cruzavam na altura da Várzea do Carmo. Jacob Penteado que morava não muito longe dali, por volta de 1910, na rua Benjamim de Oliveira, lembra que "Qualquer pancada de chuva inundava-a ... Muitas vezes, a água chegava até o peitoril da janela”. ${ }^{35}$

A região da Várzea do Carmo era "então cheia de valetas, lagoas e mato bem alto. À noite era perigoso passar por ali, devido aos marginais que pernoitavam nas moitas". ${ }^{36}$ Era toda uma área que não era bairro, embora pessoas dormissem ali, como testemunha o autor, pertencente a uma família italiana pobre. E isso caracterizou os arredores como lugar lúgubre, com habitações coletivas, improvisadas e sujeitas a enchentes.

O Brás foi então urbanizado, tendo recebido imigrantes italianos em abundância. Essa zona de transição entre a várzea e o bairro continuava precária, concentrando a população mais pobre, na sua maioria negros e mestiços. No bairro "construíram-se fábricas, chaminés por toda a parte, a forja, o malho, os teares, os motores, os dínamos". ${ }^{37}$ Isso o tornou conhecido como bairro italiano, embora a presença de negros também fosse maciça. Após a abolição da escravatura em 1888, a cidade se mostrou destino possível, onde a demanda por serviços atraía essa população abandonada à própria sorte, parte dela se dirigindo à região da várzea. O Brás, aos poucos, passa a ser iden- 
tificado com a modernidade da indústria, enquanto a Várzea do Carmo é vista como bolsão de miséria que impede a cidade de ser moderna.

Nas imediações do bairro, por sua vez, as ruas não tinham calçamento e, com exceção das vias principais, não havia fornecimento de energia elétrica ou outros serviços. A despeito de tais condições, toda a região passou a abrigar casas modestas, não raro coletivas, avizinhadas de chaminés fumegantes e fumacentas que impregnavam o ar, legando ao local uma das maiores taxas de mortalidade infantil da capital do café. ${ }^{38}$

Suas ruas eram muito movimentadas, sobretudo nas proximidades da Central do Brasil ${ }^{39}$ e da hospedaria dos Imigrantes, motivo pelo qual havia várias pensões na região. ${ }^{40} \mathrm{O}$ cronista mostra aqui, com o roteiro de José, um lado da cidade cujas políticas de saneamento e controle não pareciam fazer efeito.

Pelas ruas insalubres o rapaz segue até as margens do rio, quando é visto por um cabo que ao salvá-lo rouba-lhe a morte e o papel principal da crônica, o de herói. Afinal, parece que José queria um lugar nos jornais, cercado como podia de elementos cênicos. Tentou o suicídio justamente quando alguém passava, alguém da 'lei', que não podia se esquivar de socorrê-lo. Não escolheu um lugar isolado e suficientemente alto. Assim, a cidade se converte em palco para os dramas de pessoas que, como José, estavam integradas a essa rede de comunicação e controle instituída pela ação das autoridades e da imprensa. Como Oswald de Andrade diz na epígrafe, sempre "Havia olhos vigilantes de torres, fixos, longe". ${ }^{41}$

A ordem comum das coisas é rompida pelo fait divers. De uma situação de normalidade - o casamento entre dois jovens - ele leva o leitor à exceção e, ao fim, o drama social traduzido em drama estético volta à sua normalidade: a chegada das autoridades, a tomada de declarações legais. A ordem perturbada é controlada pelas atitudes repressoras e disciplinadoras.

A imprensa representa José Quintino, a operária e o moreno alto como o que chamamos de degenerados: pobres, inaptos, inferiores, loucos, de má índole, com comportamentos desviantes, cáften sedutor, suicida a contrastar com o equilíbrio e altruísmo do herói Zoroastro.

Muitos dos contemporâneos clamaram contra a divulgação desse tipo de notícia nos jornais. ${ }^{42}$ Com nossa análise vimos como o fait divers sedimentava estigmas já difundidos na sociedade, como a confirmar o lugar do 'outro' em oposição ao cronista e, provavelmente, a alguns tipos de leitor. Mas, ainda que servisse de confirmação aos estigmas, o jornalista era acusado de, 
assim, multiplicar as chances de os suicídios serem copiados, ao divulgá-los de forma tão ruidosa.

As autoridades, assim, se voltam contra o que julgavam uma ameaça à ordem estabelecida, onde as estruturas sociais se viam ameaçadas por tensões que afloram pelo desvio. Os suicídios por amor são vistos, nesse contexto, como desvios, por onde emergem novos estratos da vida social. Era o sintoma de uma cidade que crescia de forma acelerada e que dava sinais de descontrole. E o drama social ${ }^{43}$ vem à superfície através do submundo representado nos jornais.

É dessa forma que um Relatório de Justiça de São Paulo, relativo ao ano de 1894, se articula com o fait divers que analisamos, publicado anos depois. Vejamos primeiramente o que o texto nos traz:

Infelizmente os casos de suicídio foram mais numerosos do que no ano passado.

15 foram os indivíduos que realizaram o sinistro intento de privar-se da vida e 5 os que contra a mesma tentaram. A estatística portanto, é a seguinte:

Suicídios...............15

Tentativas ............... 5

Os meios empregados nestes 20 casos foram os seguintes:

Arma de fogo............ 15

Veneno $\ldots . . . . . \ldots \ldots . . . .3$

Asfixia por submersão $\ldots \ldots 1$

Instrumento cortante $\ldots \ldots 1$

Procurando estudar a causa desse acréscimo o investigador só pode explicálo pela publicidade na imprensa dos casos de suicídio nos seus menores detalhes, muitas vezes ridículos.

Na verdade, a imprensa de São Paulo não tem levado em conta o perigo de tais notícias, ainda quando mesmo esteja certa do incontestável contágio moral do suicídio, principalmente em relação aos indivíduos apenas púberes, nos quais a superexcitação nervosa própria da idade, despertando sensações novas exageram os sentimentos de amor.

Dos 15 suicídios verificados apenas 5 estão fora desta última causa; esses ligaram-se a um fenômeno de patologia mental, demonstrado por inquéritos policiais e por documentos deixados pelas vítimas. 
Em um deles a vítima, o árabe Miguel Corone, além de recomendações extravagantes, relatou em seus escritos a história de seus sofrimentos de sorte a não deixar dúvidas, no conceito dos médicos, que se tratava de um caso de periencefalite com mania suicida.

Nestes casos parece que não é possível obstar o suicídio, visto como é ele um fenômeno mórbido.

Felizmente esses casos são pouco freqüentes. O silêncio sobre todos eles seria, entretanto, sempre benéfico, porquanto deve obstar os suicídios por amor e os causados pela chamada loucura transitória, quase sempre conseqüente do alcoolismo.

Oxalá quisesse a imprensa paulista prestar à sociedade o grande serviço de calar tão tristes fraquezas. ${ }^{44}$

Talvez cause certo estranhamento ao leitor de hoje a relação entre aumento de casos de suicídios, loucura, 'sentimentos de amor', imprensa e crime.

O tom empregado é de repreensão e, tal qual o Anuário Estatístico e Demográfico citado anteriormente, visa uma ação disciplinadora, neste caso, em relação à imprensa, tanto no conteúdo como na maneira em que são narradas as notícias de suicídios, sobretudo de suicídios por amor. Quase 15 anos depois, como vimos no fait divers analisado, a imprensa mantinha o sensacionalismo, dando 'publicidade' aos suicídios, sobretudo aos passionais, onde poderia aplicar com mais facilidade os recursos da ficção.

Uma forma de levantar questões sobre o que há nas entrelinhas desse Relatório de Justiça é entendê-lo como parte de uma ampla tentativa de ordenação do estado e, em especial, da cidade de São Paulo em um contexto de crescimento acelerado no qual os profissionais do direito, da medicina, da psiquiatria, do sanitarismo, da engenharia urbana, políticos e pensadores sociais em geral são chamados a formular teorias e a agir sobre os problemas apresentados com a urbanização, em uma grande missão civilizadora.

Acusado de negligenciar seu poder de influência, o jornalista é intimado a se engajar nessa mesma missão como as demais autoridades.

$\mathrm{O}$ ato de se matar é visto pelo relator da Secretaria da Justiça como resultado ou da paixão exagerada, entendida como gradação da loucura, ou da loucura no seu sentido mais terrível, a morbidez, mal sem cura, um caso perdido, uma doença irreversível. Aproxima o suicídio das moléstias contagiosas, só que no plano moral, e faz um recorte de idade, preocupando-se com os jovens, considerados mais suscetíveis.

O fato de dados sobre suicídios estarem em um relatório do poder judi- 
ciário o faz ser entendido como crime. Embora o suicídio não possa ser punido como crime, as circunstâncias que o envolvem podem gerar a abertura do processo, levando-o para o âmbito da justiça criminal, visto que a indução ao suicídio, esta sim, é crime previsto no código penal da época.

Tratados como exceções — "Felizmente esses casos são pouco freqüentes” —, confirmam a regra, ou seja, o que é visto como 'normalidade' em oposição à aberração que significa o suicídio. Enfim, a ligação entre suicídio, crime e loucura era um argumento facilmente usado para estigmatizar qualquer um que ousasse romper com as normas de civilidade.

É inadmissível, nesta ordem que se coloca a missão de construir uma nação civilizada e voltada para o progresso, a leitura cuja suposta influência atinge a juventude tornando-a improdutiva, com a total anuência de um órgão central na constituição da identidade nacional.

Todo esse processo de intervenção urbana se constitui sob influência européia, ganhando características próprias no contexto brasileiro.

O que vimos no fait divers que conta a tentativa de suicídio de José foi um desfilar de estigmas incutidos a essas pessoas pobres que aparecem nas notícias do cotidiano. E tais representações não apareceram repentinamente. Quando o repórter, em 1910, constrói sua narrativa, ele obedece a uma tradição que já pode ser observada no Relatório de Justiça de 1894 articulando elementos residuais da história. ${ }^{45} \mathrm{~A}$ temporalidade do passado se sobrepõe à do presente na representação da cidade e traz consigo parâmetros que obedecem à especificidade do caso brasileiro.

A seguir tratamos um pouco sobre a trajetória dessas idéias e como elas culminam na prática revelada pelo relator de tentativa de uma intervenção oficial nas questões sociais mais diversas.

\section{ORDEM NA CIDADE}

A historiografia sobre o tema cidade tem sido enfática em demonstrar o aparato montado pelo Estado e outras instâncias de poder na tentativa de achar soluções para os problemas urbanos surgidos, sobretudo, após a industrialização. ${ }^{46}$

Cidades como São Paulo também sofrem as conseqüências de um crescimento acelerado na passagem do século XIX para o XX, derivado em grande medida da revolução científico-tecnológica ocorrida pouco antes em solo 
europeu e que inaugura uma nova fase do capitalismo industrial, baseado em novos recursos energéticos. ${ }^{47}$

Assim, com a capacidade de produção multiplicada, a expansão de mercados consumidores se fazia urgente, levando a Europa ocidental a redimensionar sua influência sobre antigas áreas coloniais, incluindo a América Latina. ${ }^{48}$ A 'ocidentalização' era patente e compulsória. ${ }^{49} \mathrm{E}$ se manifestava tanto na invasão de produtos europeus nas sociedades tradicionais como na implantação de novos padrões de comportamento que refletiam essa nova sensibilidade ${ }^{50}$ de modo a demarcar os territórios sob influência na era póscoloial..$^{51}$

O Brasil, produtor de matérias-primas, se insere nesse contexto como agro-exportador plantando e exportando café. São parte desse processo a crise gerada pela Guerra do Paraguai, a abolição da escravidão e a substituição da mão-de-obra escrava pela assalariada, o movimento e o partido republicanos, todos fatores que culminariam na Proclamação da República. ${ }^{52}$

O Rio de Janeiro, capital, desde o Império conheceu um acentuado processo de urbanização que, após 1870, em razão do contexto aqui descrito, adquire maior relevo. Mas é São Paulo que representa melhor o crescimento acelerado, mergulhando seus habitantes em espirais alucinantes de transformação. De vilarejo que conservava aspectos coloniais, torna-se repentinamente grande cidade que, embora não fosse industrial, possuía fábricas e mão-de-obra farta proporcionada pelas recentes levas migratórias, ex-escravos e nacionais pobres. Porém, vários dos problemas urbanos apresentados por grandes cidades ocidentais como Londres e Paris ${ }^{53}$ assolaram também a capital do café.

Com o inchaço, a cidade de dimensões rurais teve suas terras privatizadas, acentuando a segregação espacial e fazendo mais presente a intervenção oficial. ${ }^{54}$ Centro administrativo para onde convergiam os interesses das camadas ligadas à produção cafeeira, em pouco tempo alcança o Distrito Federal em importância e tamanho.

Como centro econômico republicano, São Paulo assiste a um crescimento repentino, com pessoas vindo de todos os cantos do mundo procurar oportunidade de sobrevivência. A imprensa e, em especial, os maiores jornais da época, O Estado de S. Paulo e o Correio Paulistano, lídimos representantes da elite cafeeira, registram esse período como um momento em que a cidade torna-se modelo de civilização, submetida a sucessivas reformas urbanas que dão uma aparência européia às ruas.

Nela a circulação desse grande número de indivíduos e de mercadorias deveria ser livre, mas seu traçado urbano teria de satisfazer, ao mesmo tem- 
po, a necessidade de conter os "grupos ameaçadores" ${ }^{55}$ A concepção mecânica do mundo se revelou uma realidade assustadora, e os habitantes da cidade foram submetidos compulsoriamente ao ritmo do maquinismo. $\mathrm{O}$ indivíduo foi esvaziado de sua identidade e tornou-se mais um em meio à multidão que, autômata, obedecia aos fluxos ordenados. ${ }^{56} \mathrm{O}$ aumento do número de suicídios parece ter sido uma das expressões mais dramáticas de reação a essas mudanças bruscas e desagregadoras a que a cidade assistiu. ${ }^{57}$

Mas a representação da cidade de São Paulo pelos seus contemporâneos não tem um único sentido. Ela oscila entre uma visão positiva, ufanista, em que signos do progresso aparecem ligados ao crescimento urbano, e uma representação negativa, na qual o crescimento acelerado e a dificuldade das autoridades responsáveis em dar conta dos problemas surgidos em conseqüência dessa explosão são vistos como ameaça constante à ordem e empecilho para o adequado desenvolvimento. ${ }^{58}$

Esse é o caso do Relatório de Justiça apresentado. São várias as questões que esse documento de época suscita. O discurso do relator se insere no rol das preocupações com o crescimento da cidade que multiplica também os casos de suicídios. Já se vê aí uma tentativa em sistematizar dados na busca de uma compreensão do processo pelo qual a sociedade passava, tendência esta que vai aumentar no decorrer do século XX com a elaboração de relatórios cada vez mais detalhados.

Ao acusar a imprensa, o relator está se referindo a uma nova fase da tipografia que também é parte do processo de urbanização, se agregando à diversidade de uma nascente sociedade de massas. Aumenta o volume e a padronização da produção, o preço do produto final diminui, o aperfeiçoamento técnico possibilita o aumento das tiragens e a organização mercantil da produção transforma definitivamente livro e jornal em mercadoria, com o conseqüente aumento da circulação. ${ }^{59}$

Os fait divers a que ele se refere de maneira depreciativa são elementos que exercem a função de aumentar as vendas de jornais, como vimos, com temas e estrutura já bastante íntimos do leitor. Uma estrutura permeada pela oralidade, permitindo a leitura em voz alta e a multiplicação do alcance do texto, arregimentando para o jornal não só o leitor tradicional, ao buscar uma “conexão com os modos de expressão popular", articulando o resgate da memória e os ditames de uma demanda. ${ }^{60}$

Daí ele julgar que o alcance das notícias, multiplicado pelo poder de seu formato, também apresenta uma capacidade de contágio, mostrando como o relator compartilha as idéias difundidas pelas teorias européias, aqui aporta- 
das desde meados do século XIX, e que continuam tendo ampla difusão no decorrer do século XX. ${ }^{61}$

Os estigmas apontados pelo jornalista na crônica "Mais um desesperado" são também resultado dessa sedimentação de referências culturais que sobrepõem a temporalidade do século XIX à do século XX, redimensionando-as.

\section{A 'LEPRA' MORAL}

Existia no Brasil dessa época um amplo debate sobre o caráter nacional brasileiro.

Iniciado com a emancipação política, e retomado com ardor nos projetos abolicionistas e republicanos, esse debate esteve cercado pela fusão peculiar das idéias liberais e evolucionistas. ${ }^{62}$

A aceitação das doutrinas do darwinismo social, que partem desse discurso científico, implicava o reconhecimento da inferioridade 'natural' daqueles que não estavam absolutamente 'adaptados' ao meio em que viviam. Isso foi usado pelo imperialismo europeu, que justificava assim o domínio ocidental. ${ }^{63}$ Todos aqueles que não se enquadravam no modelo de indivíduos bem-sucedidos, não só materialmente mas também socialmente, eram dados como inferiores:

os pobres eram pobres porque biologicamente inferiores e, por outro lado, se cidadãos pertenciam às 'raças inferiores', não era de se espantar que eles permanecessem pobres e atrasados ... O liberalismo não tinha nenhuma defesa lógica diante da igualdade e da democracia, portanto a bandeira ilógica do racismo foi levantada: a própria ciência, o trunfo do liberalismo, podia provar que os homens não eram iguais. ${ }^{64}$

No caso brasileiro, a discriminação de classe também se confundia com a discriminação de cor, sendo escravos e mestiços o alvo dos primeiros racistas. A despeito, porém, da crença de um branqueamento possível a partir da introdução do "elemento estrangeiro", branco e europeu, logo a ação disciplinadora também se volta contra os novos imigrantes, àqueles que consigo trouxeram a "lepra da luta de classes". ${ }^{65}$

Esse processo se desenrola em paralelo à intervenção oficial na nova cidade, cujas habitações coletivas são o local onde pobreza e sujeira se equivalem, tornando-se sinônimos de degeneração e patologias físicas (doenças in- 
fecciosas) e morais (crime, vícios, loucura). ${ }^{66} \mathrm{~A}$ higiene passa a atuar tanto no espaço público como no espaço privado, seja ele a fábrica ou a habitação. ${ }^{67}$

O processo de expansão urbana em São Paulo coincidiu em parte com a emergência do regime republicano, cujo programa, dada a influência da doutrina positivista, concentrou suas atenções no binômio família/cidade, base da proposta de estruturação do Estado, em que o conceito de pátria se baseava na família. Esta era vista mais do que nunca como o sustentáculo de um projeto normatizador, cujo desenvolvimento reequacionou seu papel e sua inserção social na cidade, já que a nova família foi estimulada a desenvolver práticas sociais que se adaptassem à modernidade, ao 'civilizado'.

Esse período de efervescência do processo de urbanização em São Paulo coincidiu com o momento de institucionalização da medicina como produtora de um saber como teoria e prática ... Era preciso mudar hábitos e atitudes, de tal modo que o papel do médico tornou-se decisivo na configuração das pautas normativas. $^{68}$

A culpa da moléstia é atribuída ao indivíduo, deslocando a procura das causas da 'doença' para o 'doente', ${ }^{69}$ critério cuja raiz encontra-se no determinismo moral - o contágio pela leitura, o desequilíbrio mental, a raça, a idade, o clima. Para detectar tais idiossincrasias eram usados critérios de nupcialidade, gênero, meios empregados, nacionalidade (etnia) e idade. No Anuário Estatístico da Seção Demográfica de 1900, os suicídios aparecem como "afecções produzidas por causas exteriores", o que permanece em 1903, quando vêm listados junto a outros tipos de doenças como febre tifóide, influenza, varíola e sarampo.

Em 1918 o Anuário traz um apêndice sobre os suicídios, com quadros estatísticos, que continuarão a ser publicados nos relatórios subseqüentes. Já os quadros publicados em 1920 acumulam os dados dos anos anteriores. Neles, as classificações de fundo orgânico e de ordem moral não se excluem.

Apesar de todo esse esforço, a ação parece se restringir ao discurso, de acordo com a nota a seguir publicada n'O Estado de S. Paulo em 1917, pouco antes de estourar a greve anarquista que imobilizou a cidade.

\section{Polícia de Costumes}

O Dr. Virgílio Nascimento, segundo delegado auxiliar continua a agir ... apesar dos escassos recursos que lhe dá o governo, vem prestando os mais relevantes serviços à campanha de regeneração, em tão boa hora promovida. 
A polícia do Rio acha-se empenhada numa ativa campanha contra os cáftens... Há dias tivemos ocasião de nos referir aqui à intermitência de certas 'campanhas' a que todos estamos habituados e que já não causam impressão a ninguém. De quando em quando, sobretudo nos começos de cada administração policial ou municipal, é contar pela certa: surge a campanha contra o jogo ou qualquer outra série. Também com a mesma facilidade desaparece um belo dia, e não se fala mais nisso ...

É o caso de fazer votos, porque, embora se trate do Rio, o assunto nos interessa por alguma coisa mais do que uma simples questão de princípios. São Paulo, pelas proximidades da capital da República, está por assim dizer incluído no raio de ação da polícia carioca. ${ }^{70}$

Vemos como na mesma medida em que a imprensa é acusada de levar pessoas a praticar o suicídio, ela serve de tribuna aos críticos que procuram contribuir com suas ações e opiniões para o ordenamento da sensação de caos gerada pela urbanização acelerada.

A "utopia da cidade disciplinar" não se restringe, portanto, à imposição de um conjunto de normas a serem impostas no interior da fábrica ou fora dela. Por várias outras instâncias a ação racionalizadora de costumes se imiscui, tendo a imprensa um papel central como difusora de valores. ${ }^{71}$ De qualquer forma, os órgãos de controle viam o jornalista de 'processos' e o fait divers como agentes desestabilizadores e tinham como base, sem dúvida, tais teorias.

Porém, estudos sobre a cidade mostram como saber médico e engenharia estão presentes no nascimento do urbanismo moderno, principalmente no que diz respeito ao sanitarismo, através de uma ação oficial que mobilizava igualmente a camada política, ${ }^{72}$ criando uma identificação entre pobreza e patologia, que não se restringia apenas ao ambiente físico, mas também moral.

Às concepções de controle através de redes de comunicação que tornassem viável a logística dos fluxos de mercadoria e pessoas, assim como uma imprensa que representasse tais idéias na constituição de uma "sociedade imaginada", ${ }^{73}$ juntam-se as novas práticas de intervenção urbana de contenção das epidemias, na suas acepções física e moral.

Se num primeiro momento a ação se restringe à repressão ou à repreensão de alguns órgãos que se coloquem fora desse projeto civilizador, com a entrada do século os relatórios passam a ser mais racionalizados, enfatizando a ação profilática no lugar da repressora.

Unindo esses profissionais está a tentativa de entendimento da socieda- 
de, mas uma compreensão que, vimos, mais que perscrutar as causas sociais que estavam por trás do ato considerado criminoso, colocava a todos em um grande grupo considerado degenerado física e moralmente, degeneração esta vista como resultado da inferioridade de classe e racial.

Culpar a imprensa e os jornalistas por difundirem à maneira de romances os casos de crimes, em especial os passionais, era um boa maneira de se esquivar do verdadeiro problema, fazendo silenciar ao invés de trazer à tona a questão social aí embutida.

Marc Ferro mostra como em alguns casos os fait divers são ignorados justamente por revelarem aquilo que a sociedade quer ocultar.

Mais créer des émotions n'est pas la seule fonction attribuée au fait divers. On sait qu'au Moyen Age, dans les exempla, il fut utilisé à des fins morales ou religieuses. Aux XIXe et XXe siècles, pour certains esprits 'éclairés', il sert de révélateur aux dysfonctionnements du système social ou politique; loin d'être un incident mineur, il exprime au contraire un phénomène essentiel, la nécessité pour les sociétés de modifier leurs modes de fonctionnement et les rapports entre les hommes. Emile Zola, Camus et Sartre figurent parmi les premiers écrivains qui ont ainsi utilisé le fait divers comme un signe, se transformant eux-mêmes en analystes, en historiens. Or, aujourd'hui encore, devant le fait divers, la presse adopte ces différentes attitudes. Dans le journal Le Monde, par exemple, on l'ignore; ailleurs, le même cas peut faire appel au voyeurisme ou solliciter l'analyse

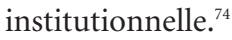

Quando o fait divers revela a necessidade de uma mudança na sociedade, necessidade esta percebida apenas por alguns espíritos esclarecidos, como afirma o autor, ele revela o drama social vivido pelas pessoas que nele se vêem representadas. No caso brasileiro, temos que no início do século XX em nossa cultura ainda estava muito presente a herança do escravismo, e o estigma legitimado pela escravidão se estende aos demais trabalhadores pobres que compõem a nova sociedade.

O medo branco das ondas negras se transfere para as 'classes perigosas', agora compostas por vagas de imigrantes de todos os tipos, de europeus a orientais, de ex-escravos vindos do interior aos pobres e mestiços nacionais, do caipira ingênuo a forasteiros espertos que ocupam a cidade se dispondo nesse teatro como personagens que deveriam tomar suas estritas posições ligadas à produção ordenada.

Assim, foram representados os personagens do fait divers que vimos no 
início deste artigo como loucos, inaptos, lascivos, suicidas, signos estes que se ligam diretamente à sua posição social dada também pelo endereço, lugar que ocupavam na cidade e pela descrição de uma parte da cidade pela qual circulavam, os bairros pobres, as margens do rio insalubre e o cinema popular.

Todos esses sinais vistos como resultado da degeneração moral que macula a imagem de civilização e controle tão avidamente buscada pelas autoridades.

Em um processo descontínuo se sobrepõem, de um lado, o aumento do descontrole e da criminalidade em geral e, de outro, as tentativas e inúmeras 'campanhas' com o objetivo de conter o caos, visando não somente o controle produtivo mas também eugênico.

Ainda que a crônica de fait divers não seja uma fonte que privilegie a veracidade, podemos levantar algumas questões, como vimos, da representação que os contemporâneos faziam da cidade de São Paulo, das camadas mais pobres da sua população, assim como do lugar estratégico da imprensa e das comunicações nas políticas higienistas. Quando a imprensa foge a essa responsabilidade é chamada a mudar o tom, como fez o relator oficial.

Um relatório que, sendo de fins do século XIX, dialoga com o passado, na medida em que recupera teorias já difundias aplicando-as ao novo contexto. E que se projeta sobre o futuro, em sobreposições temporais, no discurso do cronista que reproduz as idéias de degeneração que unem a questão física à moral.

Ambos os discursos não eram atitude isolada, ao contrário, faziam parte de uma ação múltipla e sincronizada, pautada pela influência de teorias de cunho 'científico' que têm sua base constituída nas características de abstenção, resignação, ordem sistemática, economia de energia para a produção e o garante dos fluxos. ${ }^{75}$

Um controle higiênico e eugênico dos dramas da cidade de São Paulo que o fait divers vinha, inconvenientemente, revelar.

\section{NOTAS}

${ }^{1}$ ANDRADE, Oswald de. Os Condenados. São Paulo: Ed. Círculo do Livro, s.d. p.203.

${ }^{2}$ Danilo Angrimani debate os conceitos de fait divers e sensacionalismo. Espreme que sai sangue: um estudo do sensacionalismo na imprensa. São Paulo: Summus, 1995. Ainda sobre o fait divers, é possível encontrar referências, no que toca aos estudos nacionais, em MEYER, Marlyse. Folhetim, uma história. São Paulo: Companhia das Letras, 1996.

${ }^{3}$ São faces do sensacionalismo também o folhetim e a literatura de sensação. Cf. MEYER, 
Marlyse, cit.; Cf. EL FAR, Alessandra. Páginas de Sensação - literatura popular e pornográfica no Rio de Janeiro (1870-1924). São Paulo: Companhia das Letras, 2004.

${ }^{4}$ Nos Estados Unidos esse tipo de jornalismo ficou conhecido como 'jornalismo amarelo', cor do personagem de história em quadrinhos Yellow Kid usado para vender jornais como o World e o Journal (fim do século XIX). No Brasil o termo usado é 'imprensa marrom', uma apropriação da expressão francesa empregada pejorativamente para designar veículos cuja credibilidade é duvidosa. ANGRIMANI, Danilo, cit., p.22; EMERY, Edwin. História da Imprensa nos Estados Unidos: uma interpretação da história do jornalismo. Rio de Janeiro: Lidador, 1965. p.233.

${ }^{5}$ Este artigo é parte dos resultados de nossa pesquisa de doutorado em história social sobre fait divers publicados no jornal O Estado de S. Paulo na passagem do século XIX para o $\mathrm{XX}$. Alguns dos apontamentos dizem respeito à nova pesquisa em andamento, sobre história do sensacionalismo no Brasil, realizada no Centro de Estudos da Oralidade (CEO) da pós-graduação em Comunicação e Semiótica (COS) da PUC-SP. Cf. GUIMARÃES, Valéria. Notícias diversas: suicídios por amor, 'leituras contagiosas' e cultura popular em São Paulo nos anos dez. Tese (Doutorado) — Depto. de História, FFLCH, USP, São Paulo, 2004.

6 "Inclassable, le fait divers était ainsi jeté au rebut". FERRO, Marc. Fait divers, Fait d'histoire. Annales. Histoire, Sciences Sociales, v.38, n.4, 1983, p.821.

${ }^{7}$ Cf. BARTHES, Roland. Crítica e verdade. São Paulo: Perspectiva, 1970.

${ }^{8}$ Cf. AUCLAIR, George. Le Mana Quotidien - structures et fonctions de la chronique des fait divers. Paris: Anthopos, 1970.

9 “...le fait divers fut analysé dans ses structures et défini comme un fait 'sans contexte', 'sans environnement' - qui se comprend le lui-même, 'qui ne nécessite pas de savoirs pour être intelligible’.”. FERRO, Marc, cit., p.821.

10 "Não é possível manter ainda uma distinção ingênua e radical entre res factae e res fictae, como se fosse possível chegar, por meio de documentos reais, a uma verdade incontestável e, por outro lado, por meio de artifícios, ficar no mundo da fantasia ou pura invenção.", PESAVENTO, Sandra. História \& literatura - uma velha-nova história In: Revue Nuevo Mundo, disponível em nuevomundo.revues.org/document1560.html.

${ }^{11}$ Cf. SEVCENKO, Nicolau. Literatura como missão: tensões sociais e criação cultural na Primeira República. São Paulo: Brasiliense, 1989. 3.ed.

${ }^{12}$ O Estado de S. Paulo, 13 ago. 1910.

${ }^{13}$ PORTO, Antônio Rodrigues. História da cidade de São Paulo (através de suas ruas). São Paulo: Carthago, 1992. 2.ed. p.109; SEVCENKO, Nicolau. Orfeu extático na Metrópole: São Paulo, sociedade e cultura nos frementes anos 20. São Paulo: Companhia das Letras, 1998. p.115.

${ }^{14}$ LEME, Marisa Saenz. Aspectos da evolução urbana de São Paulo na Primeira República. Tese (Doutorado) - Depto. de História, FFLCH, USP, São Paulo, 1984. p.147.

${ }^{15}$ Ibidem, p.155.

${ }^{16}$ Ibidem. 
${ }^{17}$ RAGO, Margareth. Do cabaré ao lar: a utopia da cidade disciplinar, Brasil 1890-1930. São Paulo: Paz e Terra, 1997. 3.ed. p.12-3.

${ }^{18}$ SCHWARCZ, Lilia. O espetáculo das raças: cientistas, instituições e questão racial no Brasil, 1870-1930. São Paulo: Companhia das Letras, 2001.p.151.

${ }^{19}$ Anuário Estatístico de Seção de Demografia - ANO X - 1903. Diretoria do Serviço Sanitário do Estado de São Paulo, São Paulo, 1904.

${ }^{20}$ RAGO, Margareth, cit., p.80.

${ }^{21}$ A Fábrica Matarazzo pertencia ao italiano Francisco Matarazzo. Já a essa época contava com o Moinho Matarazzo, inaugurado em 1900 e instalado no Belenzinho. Um ano depois, foi criada a Tecelagem de algodão Mariângela, a primeira empresa do grupo no setor têxtil, de cuja costela sairiam a Fiação, Tecelagem e Estamparia do Belenzinho, inaugurada em 1911, ano da criação das Indústrias Reunidas Francisco Matarazzo, que deu início ao grande império industrial do empreendedor italiano. Cf. LEME, cit.

${ }^{22}$ PINTO, Maria Inez Machado Borges. Cotidiano e sobrevivência: a vida do trabalhador pobre na cidade de São Paulo (1890-1814). São Paulo: Edusp/Fapesp, 1994. p.96.

${ }^{23}$ BEIGUELMAN, Paula. A crise do escravismo e a grande imigração. São Paulo: Brasiliense. 1981. p.47; Cf. KOWARICK, Lúcio. Trabalho e vadiagem: a origem do trabalho livre no Brasil. Rio de Janeiro: Paz e Terra, 1994; Cf. AZEVEDO, Célia Maria Marinho de. Onda negra, medo branco: o negro no imaginário das elites século XIX. São Paulo: Annablume, 2004. 2.ed. rev. e ampliada.

${ }^{24}$ RAGO, cit., p.63.

${ }^{25}$ Ibidem, p.82.

${ }^{26}$ SALIBA, Elias. A dimensão cômica da vida privada na República In: SEVCENKO, Nicolau (Org.) História da Vida Privada no Brasil. São Paulo: Companhia das Letras, 1998. v.3, p.331.

${ }^{27}$ PENTEADO, Jacob. Belenzinho 1910 (retrato de uma época). São Paulo: Carrenho, Narrativa Um, 2003. p.171-6.

${ }^{28}$ AMERICANO, Jorge. São Paulo naquele tempo (1895-1915). São Paulo: Carrenho, Narrativa Um, Carbono 14, 2004. p.221.

${ }^{29}$ 'Ilusão', pois no cinema perdemos a noção de proporcionalidade, do ritmo dos acontecimentos, do foco real e das cores, já que não 'corrigimos' esses desníveis da percepção como faríamos na realidade. ESPINAL, Luís. Cinema e seu proceso psicológico. São Paulo: Lic, 1976. p.18.

${ }^{30}$ Ibidem, p.22.

${ }^{31}$ Ibidem, p.33.

${ }^{32}$ Ibidem, p.43.

${ }^{33}$ Cf. GUIMARÃES, Valéria. Notícias diversas: apontamentos para a história do fait divers no Brasil. Dossiê Especial: "Reportagem Policial”. Revista do Portal do Jornalismo Brasileiro 
(PJ:Br), ed. 7, 2º sem/2006. Disponível em www.eca.usp.br/profjosemarques/arquivos/ dossie7_d.htm.

${ }^{34}$ MOURA, Paulo Cursino de. São Paulo de outrora (evocações da metrópole). São Paulo: Edusp, Belo Horizonte: Itatiaia, 1980. p.297.

${ }^{35}$ PENTEADO, Jacob, cit., p.45.

${ }^{36}$ Ibidem, p.46.

${ }^{37}$ MOURA, Paulo Cursino de, cit., p.302.

${ }^{38}$ LEME, cit, p.146-50.

${ }^{39}$ MOURA, cit., p.302.

${ }^{40}$ LEME, cit., p. 152.

${ }^{41}$ ANDRADE, Oswald, cit.

${ }^{42}$ Cf. GUIMARÃES, Valéria. Leituras suicidas: análise de uma conferência de Gilberto Amado de 1910. In: ENCONTRO REGIONAL DE HISTÓRIA, XIV, Sujeito na História: práticas e representações. Anais... São Paulo: Anpuh-SP, 2004; O lugar da história. Campinas (SP): Unicamp, 2004. p.288.

${ }^{43}$ No sentido que dá TURNER, Victor. The anthropology of performance. New York: PAJ, 1988. Ver também DAWSEY, John C. Victor Turner e a antropologia da experiência. Cadernos de Campo, revista de pós-graduação de Antropologia Social, São Paulo: USP, n.13, Ano 14, 2005, p.163-76.

${ }^{44}$ Relatório da Secretaria de Justiça apresentado ao Presidente de Estado pelo Secretário Interino dos Negócios da Justiça de São Paulo — José Álvares Rubião Jr. Em 31 dez. 1894. São Paulo: Tipografia a vapor Espíndola, Siqueira \& C., 1895. p.260-1.

${ }^{45}$ DAWSEY, John C., cit., p.165. Ver também DAWSEY, John C. Leituras benjaminianas da cidade: repensando o drama social. In: CONGRESSO LATINOAMERICANO DE ANTROPOLOGIA, I. Anais..., jul. 2005, p.1-16.

${ }^{46}$ Cf. BRESCIANI, Maria Stella M. História e historiografia das cidades, um percurso. In: FREITAS, Marcos Cezar (Org.) Historiografia brasileira em perspectiva. São Paulo: Contexto, 2005.

${ }^{47}$ Como aço, petróleo, eletricidade e produtos químicos. Cf. BARRAGLOUGH, Geoffrey. O impacto do progresso técnico e científico - industrialização e imperialismo como catalisadores de um novo mundo In: Introdução à história contemporânea. São Paulo: Círculo do Livro, Zahar Editores, s.d.

${ }^{48}$ SEVCENKO, Nicolau. Literatura como missão..., cit., p.43-4.

${ }^{49}$ HOBSBAWM, Eric J. A era dos impérios - 1875-1914. Rio de Janeiro: Paz e Terra, 1989. 2.ed. p.115.

${ }^{50} \mathrm{Na}$ Europa, a formação de cidades industriais (que passaram de centro comercial a aglomerado urbano complexo) se deu no século XIX como resultado do incremento do capitalismo. BRESCIANI, Maria Stella M. Metrópoles: as faces do monstro urbano (as cidades no século XIX). Revista Brasileira de História, n.8/9, 1985, p.38. 
${ }^{51}$ SEVCENKO, Literatura como missão..., cit., p.44.

${ }^{52}$ SCHWARCZ, O espetáculo das raças..., cit, p.33-41; ver também História geral da civilização brasileira: o Brasil Republicano - estrutura de poder e economia. Tomo III, v.1, e O Brasil Republicano: sociedade e instituições, Tomo III, v.2. São Paulo, Rio de Janeiro: Difel, 1977.

${ }^{53}$ Londres e Paris foram os modelos de projetos urbanos que serviram de inspiração para várias cidades do Ocidente, incluindo Rio de Janeiro e São Paulo. Com o objetivo de sanar a desordem da cidade industrial, liberando e ordenando as caudalosas correntes demográficas, foram construídos em Londres o Regent's Park e a Regent Street, no início do século XIX e, em Paris, houve uma completa remodelação durante o Segundo Império de Napoleão III, em meados do mesmo século, pelas mãos do prefeito Barão de Haussmann, que por 17 anos implementou uma das maiores reformas que uma cidade jamais vira. Ruas e avenidas foram abertas como artérias e veias, cruzando os parques, pulmões da cidade. SENNETT, Richard. Carne e pedra: o corpo e a cidade na civilização ocidental. Rio de Janeiro: Record, 1997. p.265-73.

${ }^{54}$ Cf. ROLNIK. Raquel. Cada um no seu lugar (São Paulo, início da industrialização: geografia do poder). Dissertação (Mestrado) — FAU, USP, São Paulo, 1981.

${ }^{55}$ SENNETT, Richard. Carne e pedra..., cit., p.265.

${ }^{56}$ BRESCIANI, Metrópoles: as faces ..., cit., p.54-6.

${ }^{57}$ Em 1894 foram oito os suicídios praticados na capital paulista, sendo o coeficiente por 100 mil habitantes de 5,33. Em 1910 este índice chega a 21, com coeficiente de 6,68, tendo seu ápice em 1914, com 80 suicidas e coeficiente de 16,49. (índices do período 1894-1920). Anuário Demográfico da Seção de Estatística Demógrafo-Sanitária, ano XXVII, v.1, 1920, p.108.

${ }^{58}$ BRESCIANI, História e historiografia das cidades..., p.241. Cf. SANTOS, Carlos José Ferreira dos. Nem tudo era italiano: São Paulo e pobreza (1890-1915). São Paulo: Annablume, 1998.

${ }^{59}$ MARTINS, Wilson. A palavra escrita: história do livro, da imprensa e da biblioteca. São Paulo: Ática, s.d. p.230-6

${ }^{60}$ BARBERO, Jesús-Martin. Dos meios às mediações - comunicação, cultura e hegemonia. Rio de Janeiro: Ed. UFRJ, 2003. p.257. LYONS, Martyn. Os novos leitores no século XIX: mulheres, crianças e operários. In: CAVALLO, Guglielmo; CHARTIER, Roger (Org.) História da leitura no mundo ocidental. São Paulo: Ática, 2002. p.197.

${ }^{61}$ A noção de opinião pública já vem de fins do século XVII, mas ela toma nova dimensão num contexto de liberdade de imprensa emergindo a idéia de "psicologia das multidões" de Scipio Sighele (1868-1913) e Gustave Le Bon (1841-1931). Le Bon reproduz tais conceitos em Psychologie de Foules, de 1895. MATTELART, Armand e Michèle. História das teorias da comunicação. São Paulo: Loyola, 1999. p.15.

${ }^{62}$ Cf. AZEVEDO, Célia Maria Marinho. Onda negra, medo branco..., cit.

${ }^{63}$ SCHWARCZ, O espetáculo das raças..., cit., p.56. 
${ }^{64}$ HOBSBAWM, Eric J. A era do capital - 1848-1875. São Paulo: Paz e Terra, 1997. 5.ed., p.370.

${ }^{65}$ Cf. SCHWARCZ, Lilia Moritz. Nem preto nem branco, muito pelo contrário: cor e raça na intimidade. In: SCHWARCZ, Lilia Moritz (Org.) História da vida privada no Brasil: contrastes da intimidade contemporânea. São Paulo: Companhia das Letras, 1997. v.4.

${ }_{66} 6$ "Por fim, há uma associação que se impõe com uma insistência até então desconhecida: a higiene do pobre seria o garante da sua moralidade, e também de uma 'ordem,", VIGARELLO, Georges. O limpo e o sujo — a higiene do corpo desde a Idade Média. Lisboa: Ed. Fragmentos, 1985. p.151.

${ }^{67}$ Cf. RAGO, Margareth, cit.,; DECCA, Maria Auxiliadora G. A vida fora das fábricas: o cotidiano operário fora das fábricas, 1920-1934. Rio de Janeiro: Paz e Terra, 1987.

${ }^{68}$ MATOS, Maria Izilda S. Corpos numa paulicéia desvairada: mulheres, homens e médicos - São Paulo, 1890-1930 Revista do Programa de estudos Pós-graduados em História e do Departamento de História — Projeto História-Corpo \& Cultura, PUC, São Paulo: Educ, n.25, dez. 2002, p.383.

${ }^{69} \mathrm{Cf}$. SCHWARCZ, O espetáculo das raças..., cit.

${ }^{70}$ O Estado de S. Paulo, 22 mar. 1917.

${ }^{71}$ Cf. SCHWARCZ, Lilia Moritz. Retrato em branco e negro: jornais, escravos e cidadãos em São Paulo no final do século XIX. São Paulo: Companhia das Letras, 2001.

${ }^{72}$ Cf. BRESCIANI, História e historiografia das cidades..., cit.; Cf. SANTOS, L. A. de Castro. A reforma sanitária 'pelo alto': o pioneirismo paulista no início do século XX. Dados, Rio de Janeiro, v.36, n.3, 1993; RIBEIRO, Maria Alice Rosa. A cidade de São Paulo e a saúde pública (1554-1954). In: PORTA, Paula (Org.) História da Cidade de São Paulo, v.2. São Paulo: Paz e Terra, 2004; Cf. COSTA, Luis Augusto Maia. O ideário urbano paulista na virada do século: o engenheiro Theodoro Sampaio e as questões territoriais e urbanas modernas (1886-1903). Dissertação (Mestrado) — FAU, USP, São Paulo, 2001; Cf. CAMPOS, Cristina de. São Paulo pela lente da higiene: as propostas de Geraldo Horácio de Paula Souza para a cidade (1925-1945). São Paulo: Rima, Fapesp, 2002.

${ }^{73}$ Cf. ANDERSON, Benedict. Nação e consciência nacional. São Paulo: Ática, 1989. (Série Temas, 9).

${ }^{74}$ FERRO, Marc, cit., p.824.

${ }^{75}$ MUNFORD, Lewis, cit., p.449. 